\title{
EVALUATION OF HIGH PERFORMANCE CONVERTERS UNDER LOW DOSE RATE TOTAL IONIZING DOSE (TID) TESTING FOR NASA \\ PROGRAMS
}

\author{
Ashok K. Sharma \\ NASA, Goddard Space Flight Center, Greenbelt, MD \\ Kusum Sahu \\ Unisys Corporation, Lanham, MD
}

\begin{abstract}
This paper reports the results of low dose rate (0.01-0.18 rads( $\mathrm{Si}) / \mathrm{sec})$ total ionizing dose (TID) tests performed on several types of high performance converters. The parts used in this evaluation represented devices such as a high speed flash converter, a 16-bit ADC and a voltage-to-frequency converter.

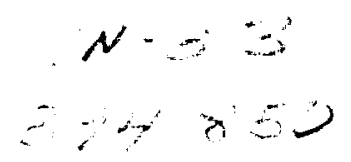




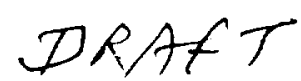

\title{
EVALUATION OF HIGH PERFORMANCE CONVERTERS UNDER LOW DOSE RATE TOTAL IONIZING DOSE (TID) TESTING FOR NASA PROGRAMS
}

\author{
Ashok K. Sharma \\ NASA, Goddard Space Flight Center, Greenbelt, MD \\ Kusum Sahu \\ Unisys Corporation, Lanham, MD
}

\begin{abstract}
This paper reports the results of low dose rate $(0.01-0.18 \mathrm{rads}(\mathrm{Si}) / \mathrm{sec})$ total ionizing dose (TID) tests performed on several types of high performance converters. The parts used in this evaluation represented devices such as a high speed flash converter, a 16-bit ADC and a voltage-to-frequency converter.
\end{abstract}

\section{Introduction}

A number of NASA programs are using commercial (non-radiation-hardened) high performance converters such as 12-16 bit resolution ADCs, 10-bit flash converters, and synchronous voltage-to-frequency converters. There are no radiation tolerance guarantees provided on these parts by the manufacturers. Most of the characterization data available on these parts either from the manufacturers or independent test organizations is high dose rate. In several recent papers on enhanced low dose rates for bipolar linear devices, concerns have been expressed about the validity of high dose rate test data and its applicability to space environment, where the actual dose rates are several orders of magnitude lower. Also, these converters, during irradiation are usually subjected to limited functional testing, e.g., in a 12-bit ADC, the devices are tested for linearity (or differential nonlinearity) and missing codes only at certain transition points and not 4096 codes that an "all codes" test requires. Similarly, the flash ADCs may not be tested at the minimum guaranteed conversion rate (e.g., 3 MSPS for AD9050).

The objective of this testing on high performance converters was to use a combination of low dose rate to simulate low dose rate space environment in combination with special tests like "all codes" and "at speed" to detect any anomalous results.

\section{Test Facilities and Procedures}

The TID testing is performed using Co-60 gamma irradiator located in the Radiation Effects Facility of NASA/Goddard Space Flight Center. The radiation dose rate capabilities within the irradiator room range from 0.001 to $1.3 \mathrm{rads}(\mathrm{Si}) / \mathrm{sec}$, and is measured using ionization chamber probe. The test devices were irradiated using static bias. The selection of total dose radiation steps for each series of tests were based on anticipated radiation sensitivity of the parts and the predicted total dose requirements for 
the program. Most commonly used irradiation steps were $2.5,5,10,15,20,30,50,75$ and $100 \mathrm{krads}(\mathrm{Si})$. The dose rate for high performance converters testing varied from 0.01 to $0.18 \mathrm{rads}(\mathrm{Si}) / \mathrm{sec}$. During some irradiation steps and after the final exposure, the parts were annealed under bias at room temperature $\left(25^{\circ} \mathrm{C}\right)$ for periods ranging from 96 168 hours.

The electrical measurements consisted of various DC parametric tests including supply currents (IDD), Input leakage currents (IL, IIH), Output voltages (VOL, VOH); functional tests such as missing codes, differential nonlinearity (DNL), integral nonlinearity (INL) measurements; and special "at speed" tests.

\section{Parts tested and Results}

\section{High Speed 10-bit Flash ADC}

A TID evaluation was performed on Analog Devices AD9050 (10-bit flash A/D converters) to determine their radiation tolerance at a combination of low dose irradiation exposure plus special functionals including all codes and at speed test program. In order to meet the minimum guaranteed conversion rate of 3 MSPS for the AD9050, ATE frequencies of greater than $16 \mathrm{MHz}$ were used. To gain more information on the missing codes, the output waveform was captured for all parts, including the control samples, after total dose steps of 20,30 and 50 krads to evaluate the impact of any missing codes on the output waveforms. Seven devices were used as test samples, along with two control samples.

After $5 \mathrm{krad}$ exposure, one device showed a missing code. During irradiations of 10,15 and $20 \mathrm{krad}$ exposure, two additional devices showed missing codes. After annealing these parts for 144 hours at $25^{\circ} \mathrm{C}$, the parts showed significant recovery in missing codes and some recovery in DNL and INL. During two additional exposures of 30 and $50 \mathrm{krads}$, most of the devices exhibited significant degradation and missing codes. After annealing the parts for 168 hours at $25^{\circ} \mathrm{C}$, the parts showed little or no recovery. During the final exposures of 75. and $100 \mathrm{krads}$, all parts continued to degrade in missing codes and showed no recovery during final annealing step of 168 hours at $25^{\circ} \mathrm{C}$. Table I provides a summary of the test results with the mean and standard deviation values for each parameter after each irradiation exposure and annealing step. Table II provides performance details for three critical parameters: Missing codes, DNL and INL.

\section{16-bit BiCMOS AVD Converter AD976}

A combination of low dose rate and special functional tests for missing codes was performed on these devices. The detailed test results will be reported in the final paper.

\section{Synchronous Voltage-to-Frequency Converter AD652}

A combination of low dose rate and special functional tests for missing codes was performed on these devices. The detailed test results will be reported in the final paper. 


\section{Conclusions}

For many high performance converters, high dose rate radiation tolerance data provided by the manufacturer may not represent the actual device hardness. The TID evaluation of these converters performed for NASA programs has been quite useful in demonstrating the need for an integrated approach that combines low dose rate testing and special functional tests for nonlinearity and missing codes. Therefore, a careful characterization of high performance converters should be performed to verify that the parts meet the application requirements in the projected mission total dose requirements. 


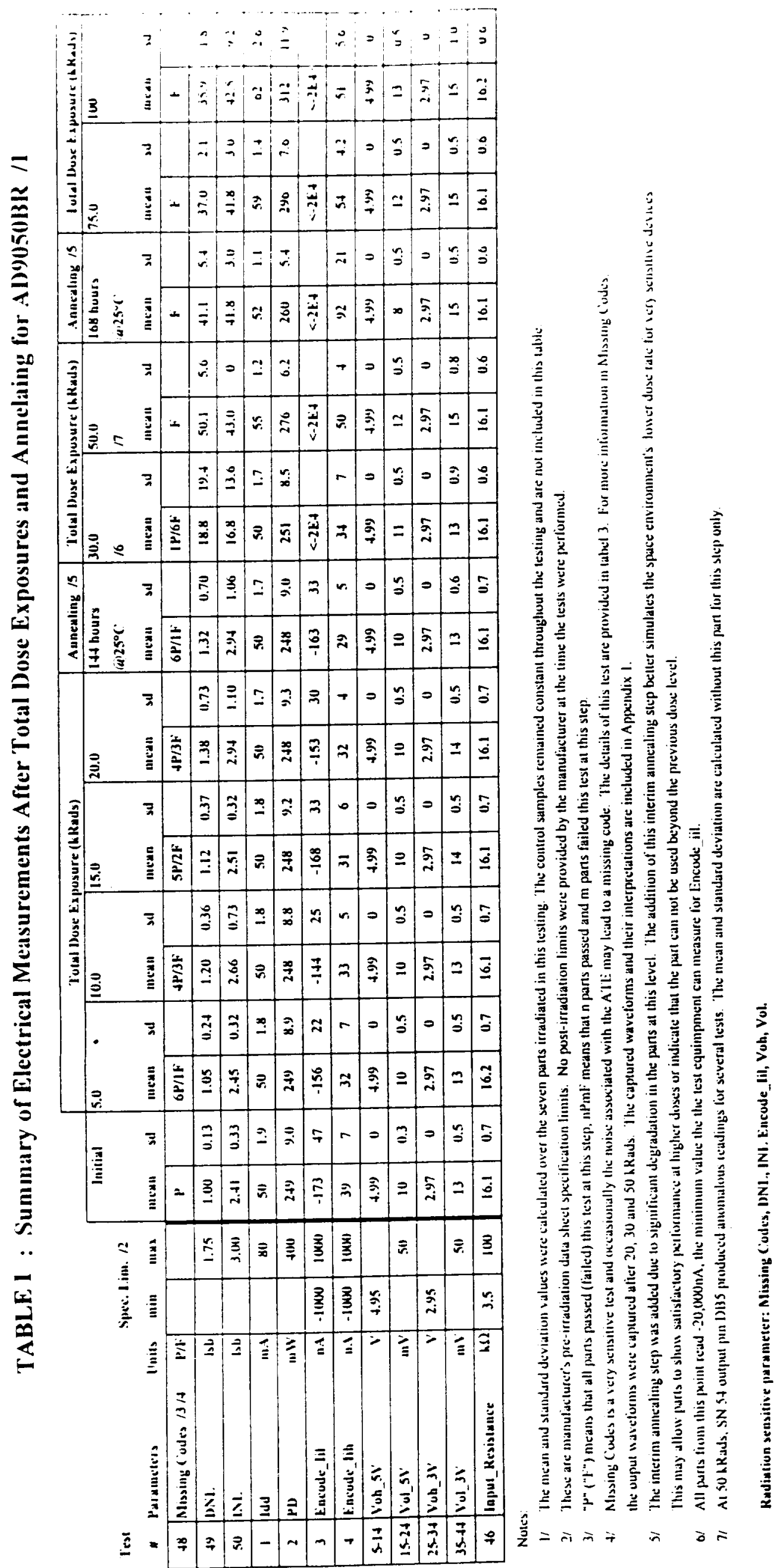




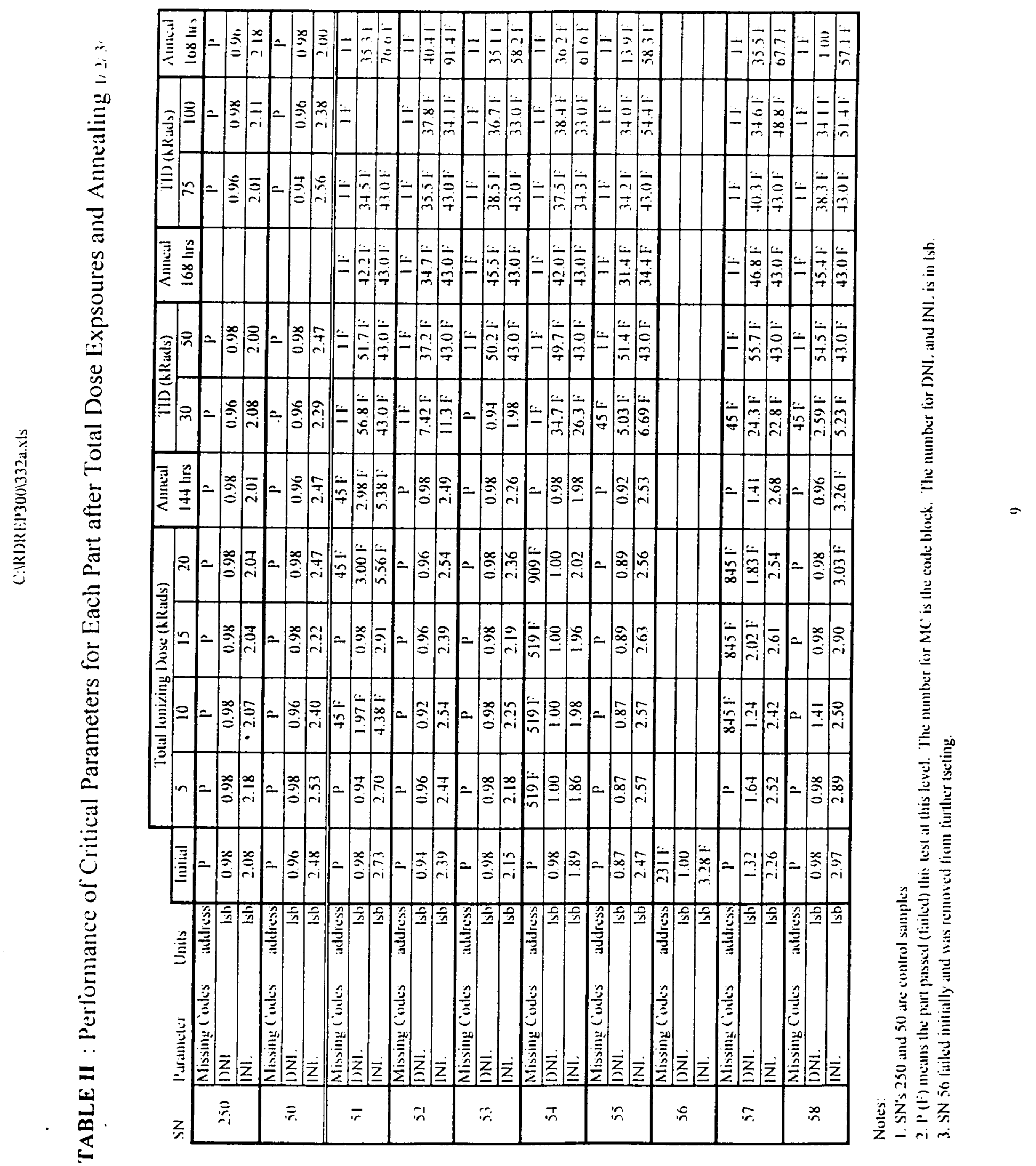



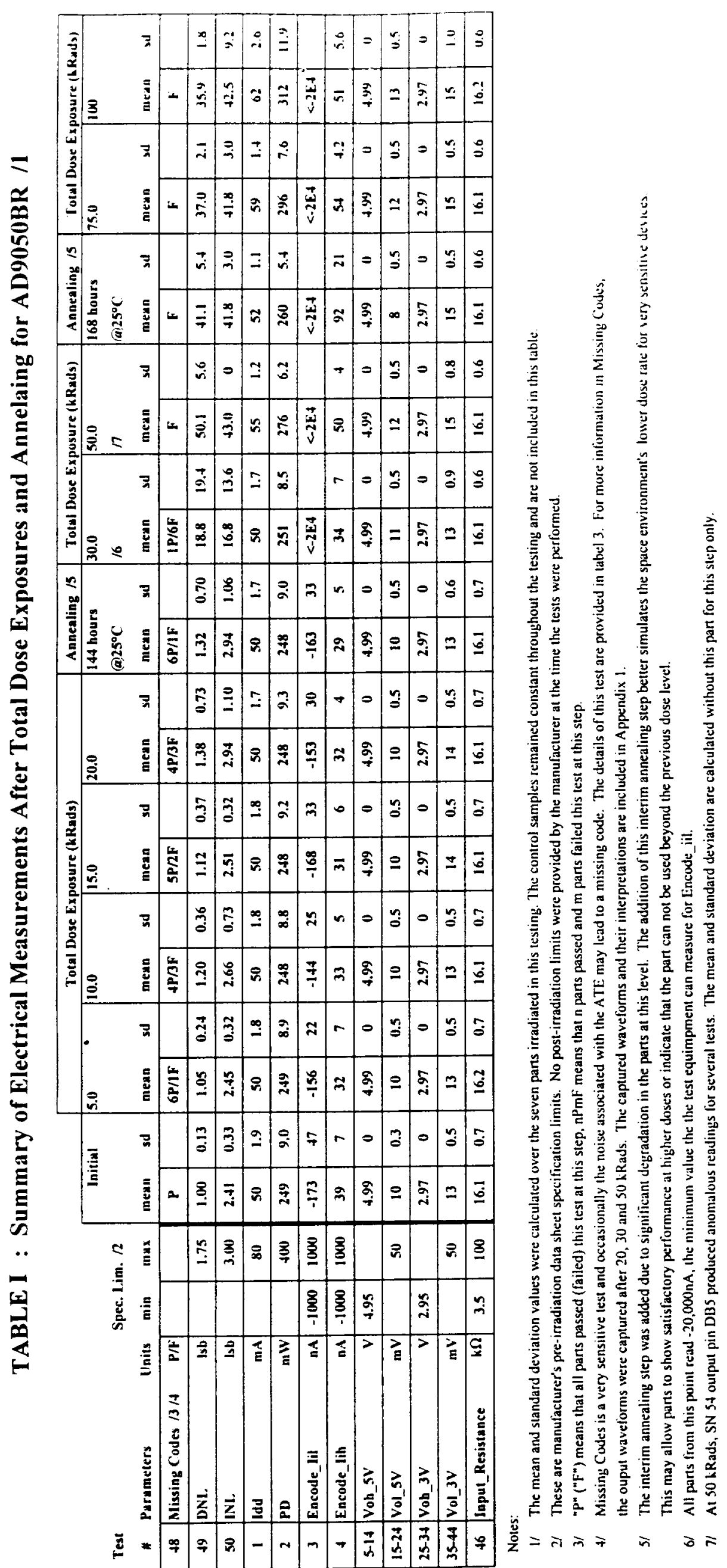


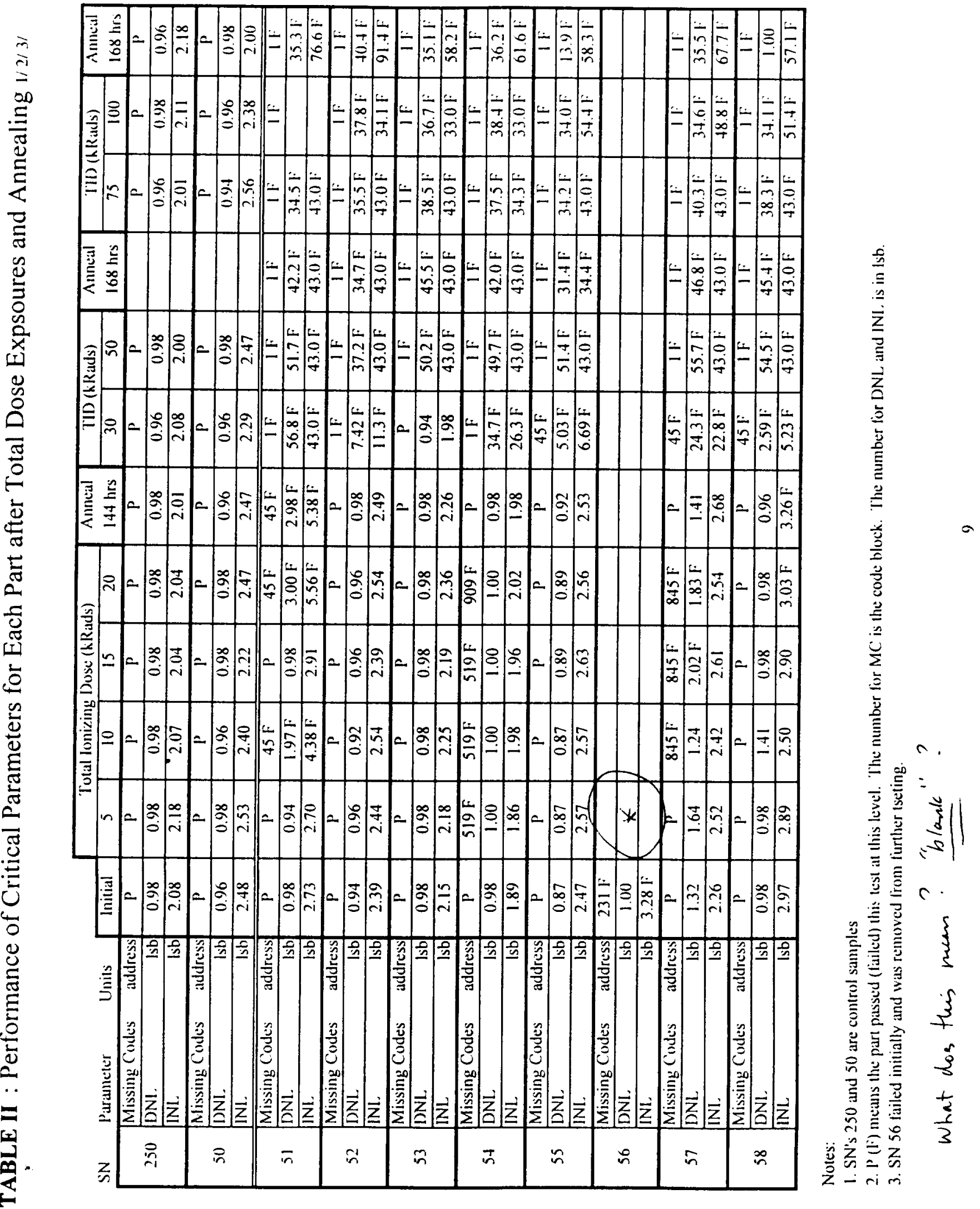

